\title{
Guided Tissue Regeneration with $\beta$-Tricalcium Phosphate and Platelet-rich Plasma for Fracture Repair in Dogs using Internal Fixation
}

\author{
Randhir Singh ${ }^{1}$, V.P. Chandrapuria ${ }^{1}$, Apra Shahi ${ }^{1}$, Madhu Swamy ${ }^{2}$, M.K. Bhargava ${ }^{1}$ and P.C. Shukla ${ }^{3}$ \\ ${ }^{1}$ Department of Veterinary Surgery and Radiology, NDVSU, Jabalpur, M.P., INDIA \\ ${ }^{2}$ Department of Veterinary Pathology, NDVSU, Jabalpur, M.P., INDIA \\ ${ }^{3}$ Department of Veterinary Medicine, NDVSU, Jabalpur, M.P., INDIA \\ *Corresponding author: R Singh; E-mail: randhirvervet2k@rediffmail.com
}

Received: 30 Sept., 2019

Revised: 15 Jan., 2020

Accepted: 22 Jan., 2020

\begin{abstract}
The study was conducted on 19 adult dogs referred for treatment of fracture in diaphyseal region of three long bones, viz, radius-ulna, femur and tibia-fibula. These dogs were divided randomly into three groups viz T1, T2 and T3. In group T1, the diaphyseal fractures of the long bones were immobilized by an internal fixation technique using reconstruction plate or locking compression plate. In group T2, $\beta$ - tri calcium phosphate granules were incorporated at fracture site after fixation. In group T3, one milliliter of PRP was administered locally at fracture site just before the closing the first suture line. Clinical and radiographic examination were also conducted during the study. There was a significant reduction in mean inflammation score at $7^{\text {th }}$ day in groups $\mathrm{T} 2$ and $\mathrm{T} 3$ and at $30^{\text {th }}$ day than 0 day in all the groups. At $90^{\text {th }}$ day, the mean radiographic score was highest for group T3 and it was followed by the score in group T2. At day $90^{\text {th }}$, a radiograph in both the views was not able to delineate the granules from osseous tissue. The mean weight bearing score was also higher in group T3 than in group T2 at $30^{\text {th }}, 60^{\text {th }}$ and $90^{\text {th }}$ post operative day showing that restoration of the function was better and earlier in groups T2 and T3 than in group T1.
\end{abstract}

Keywords: Fracture, guided tissue regeneration, tri-calcium phosphate and platelet rich plasma

The fractures can be immobilised by external immobilisation/ fixation or internal fixation. Bone plates and screws are particularly useful when post-operative comfort and early limb use are desired (Piermattie et al., 2006). The principle of guided tissue regeneration using a membrane technique has been used in periodontal surgery. By the membrane technique, cells originating from the surrounding bone are allowed to repopulate the wound without interference from other tissue types (Aaboe et al., 1993). Guided tissue regeneration with polyglactin 910 mesh is used in combination with osseous grafting to obtain new bone formation over the surgical site (Balshi et al., 1991). Autogenous bone grafting is considered the gold standard for filling bone defects even today, despite significant limitations. For this purpose, mostly, synthetic $\beta$-tricalcium phosphates ( $\beta$-TCP) or calcium phosphates from corals are used (Kasten et al., 2008).
Growth factors influence the chemotaxis, differentiation, proliferation and synthetic activity of bone cells, thereby regulating physiological remodeling and fracture healing. Numerous growth factors, such as bone morphogenetic proteins (BMPs), platelet-derived growth factor (PDGF), transforming growth factor-b (TGF- $\beta$ ), and insulin-like growth factors (IGF), have a stimulating effect on bone defect healing. Platelet-rich plasma (PRP) contains a number of these growth factors PDGF, TGF- $\beta 1$, TGF$\beta 2, \mathrm{IGF}\}$, epidermal growth factor (EGF) and epithelial cell growth factor (ECGF) in its natural composition. Considering the promising role of these new techniques in repair of fractures with bone defects, the present study was conducted.

How to cite this article: Singh, R., Chandrapuria, V.P., Shahi, A., Swamy, M., Bhargava, M.K. and Shukla, P.C. (2020). Guided tissue regeneration with $\beta$-tricalcium phosphate and platelet-rich plasma for fracture repair in dogs using internal fixation. J. Anim. Res., 10(1): 25-31. 


\section{MATERIALS AND METHODS}

The study was conducted on 19 adult dogs referred for treatment of fracture in diaphyseal region of long bones. These dogs were divided randomly into three groups as below (Table 1).

Table 1: Treatment design

\begin{tabular}{ll}
\hline Group & Treatment \\
\hline $\mathrm{T} 1(\mathrm{n}=7)$ & Internal fixation with mesh alone \\
$\mathrm{T} 2(\mathrm{n}=6)$ & $\begin{array}{l}\text { Internal fixation with mesh and } \beta \text {-tricalcium } \\
\text { phosphate }(\beta \text {-TCP) }\end{array}$ \\
$\mathrm{T} 3(\mathrm{n}=6)$ & $\begin{array}{l}\text { Internal fixation with mesh, } \beta \text {-TCP and platelet- } \\
\text { rich plasma (PRP) }\end{array}$ \\
\hline
\end{tabular}

\section{Composite mesh}

Composite mesh made up of polypropylene and polyglycolic acid was utilized for Guided tissue regeneration (GTR) of osseous tissue at fracture site. The mesh is available in size of 4 " $\times 4$ " or 4 " $\times 6$ " in a presterlised pack.

\section{$\beta$-tri-calcium phosphate}

Gamma sterilized $\beta$-tri calcium phosphate ( $\beta$-TCP) nanocrystalline granules having a particle size of 2000$3000 \mu$ were used at fracture site as an osteoconductive material to make up the bone loss.

\section{Preparation of platelet-rich plasma}

For the animals of group T3, platelet-rich plasma (PRP) was harvested by collecting $5 \mathrm{ml}$ of peripheral venous blood aseptically collected from ten healthy dogs in heparinised test tubes and pooled together. The platelet count of the pooled whole blood was determined to be $183 \times 10^{3} / \mu 1$. The blood was divided into 10 centrifuge tubes and centrifuged at $200 \mathrm{xg}$ in a routine centrifuge for 10 minutes. After, the formation of three layers (a bottom layer composed of RBC; an upper layer composed of plasma, platelets and some WBC's and an intermediate layer or buffy coat composed mostly of WBC's), the upper layer was collected with pipette. This collection was performed carefully to avoid disturbing the bottom layer of RBC and the buffy coat layer. The collected volume was approximately $3 \mathrm{ml}$ per tube. The collected sample was then transferred to an empty siliconised glass tube to be homogenized. After the sample was adequately mixed, the collected sample, approximately $30 \mathrm{ml}$ in volume, was again transferred to six centrifuge tubes and centrifuged at Relative Centrifuge Force (RCF) of 400xg for initial five minutes and subsequently at Relative Centrifuge Force (RCF) of 600xg for another five minutes. The upper half of the plasma volume, platelet poor plasma (PPP), was removed. The remaining volume of PRP was homogenized and analyzed for platelet count. The platelet count in the PRP was now determined to be $568 \times 10^{3} / \mu 1$. The PRP was stored in sterilized eppendorf tubes at $-80^{\circ} \mathrm{C}$ till use in a clinical case.

\section{Radiographic examination}

Radiographic examination in medio-lateral and craniocaudal views of the affected limb was conducted on day 0 preoperatively to optimize the implant selection and post operatively to verify the position of the fractured segments. It was followed on $30^{\text {th }}, 60^{\text {th }}$ and $90^{\text {th }}$ day to monitor implant stability and fracture healing. The radiograph was prepared on a conventional radiographic film or on Computerised Radiography (CR) System.

\section{Surgical procedure}

\section{Pre-operative preparation}

All the animals were fasted for 6 to 12 hours. The proposed site for the surgical procedure was aseptically prepared for internal fixation of fracture. Preoperative blood sample was collected and divided in two parts i.e. in EDTA coated vacutainer and in plain vacutainer.

\section{Anaesthesia}

The general anesthesia was obtained using inj. atropine sulphate@ $0.02 \mathrm{mg} / \mathrm{kg} \mathrm{I} / \mathrm{M}$ as pre-anaesthetic, followed by inj. diazepam hydrochloride@ $1 \mathrm{mg} / \mathrm{kg} \mathrm{I} / \mathrm{V}$ and induction of general anesthesia with inj. propofol $4 \mathrm{mg} / \mathrm{kg}$ $\mathrm{I} / \mathrm{V}$. After induction of the adequate level of anaesthesia in dog, endotracheal intubation was performed using a laryngoscope and a suitable sized cuffed endotracheal tube no. 6 to 7.5. Adequate anaesthetic depth was maintained 
using inhalation anesthetic agent isoflurane at minimum alveolar concentration (MAC) of 1.0-2.5\%. The flow rate of the oxygen was maintained approximately@10 ml/ $\mathrm{kg}$ b.w per minute. The semi closed or closed breathing circuit was utilized during surgical procedure as per the requirement.

\section{Instrumentation and implants}

A standard set of orthopaedic instruments was used for internal fixation with a reconstruction or locking compression plate.

Table 2: Implants used for internal fixation

\begin{tabular}{ll}
\hline Sl. No. & Name \\
\hline 1. & $\begin{array}{l}\text { Straight and T- locking compression plates }-7 \text { holes } \\
\text { to } 10 \text { holes }\end{array}$ \\
2. & Locking compression plates (T- plates) \\
3. & Self tapping cortical locking head screws $3.5 \mathrm{~mm}$ \\
4. & Reconstruction plates $2.7 \mathrm{~mm}$ \\
5. & Dynamic compression plates $2.7 \mathrm{~mm}$ \\
6. & Self tapping cortical screws $2.7 \mathrm{~mm}$ \\
\hline
\end{tabular}

The long bones radius-ulna, tibia and femur were exposed for internal fixation of fracture as described by Piermattie et al. (2006).

\section{Technique for internal fixation}

In group $\mathrm{T} 1$, the diaphyseal fractures of the long bones were immobilized by an internal fixation technique using reconstruction plate or locking compression plate. The reconstruction plate was used for internal fixation of the fracture in animals having body weight up to $12 \mathrm{~kg}$. The LCP was used for internal fixation of the fracture in animals having a higher body weight up to $30 \mathrm{~kg}$ (Fig. 1a).

The fracture ends were retrieved from incision site and were reduced manually to their anatomical position. After reduction, LCP of suitable length was placed over bone surface and held with surface using bone holding forceps. The position of the plate and its alignment was checked and optimized. The LCP sleeve was fixed in hole to be drilled. Then, the holes were drilled in bone from the plate holes using universal drill. The depth of the hole was measured with orthopaedic depth gauze. This depth was used to decide the length of screws. An appropriate screw was tightened in the hole using an orthopaedic screw driver. The same procedure was followed for each hole in proximal and distal fragment of the bone. The orthopeadic screws had purchase in minimum of six cortices of bone in one segment for rigid fixation. After fixation of the fracture, using a reconstruction plate or locking compression plate, a composite mesh was used in periphery of the bone at fracture site. Both the ends of the mesh were sutured with simple continuous sutures using polyglactin 910 No. 0 or $2-0$, so as to fit the mesh snugly around the periphery of bone at fracture site (Fig 1a and 1b).

In group T2, the diaphyseal fractures were immobilized using an internal fixation technique using a suitable plate. B-TCP granules were incorporated at fracture site in a composite mesh cylinder after achieving haemostasis. One or more pack of $0.5 \mathrm{gm} \beta$-TCP was used to make up the bone loss at fracture site.

In group $\mathrm{T} 3$, the stable internal fixation of fracture fragments was achieved and $\beta$-TCP was filled in a cylinder of composite mesh. One milliliter of PRP was administered locally at fracture site just before the closing the first suture line.

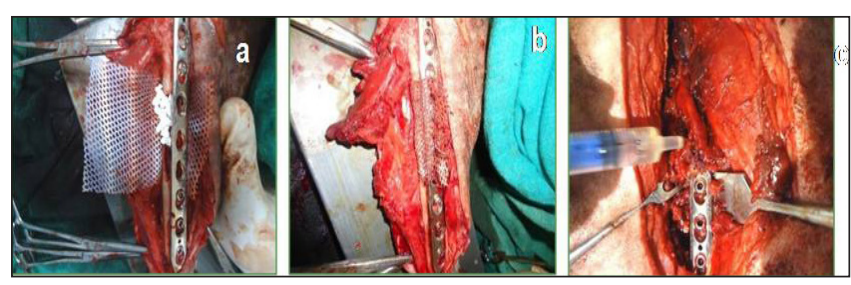

Fig. 1: Internal fixation of fracture using (a) Locking compression plate (b) scaffold of composite mesh with $\beta$ - tri calcium phosphate $(\beta-\mathrm{TCP})$ and (c) application of Platelet rich plasma (PRP)

\section{Rectal temperature}

The rectal temperature of the dogs ranged from 101 to $103^{\circ} \mathrm{F}$ at time of presentation of animals with fracture. The mean rectal temperature was non-significantly $(p>0.05)$ higher at 0 day in three groups. Desouza (2012) has also reported a higher rectal temperature in dogs at day 0 pre-operatively. The increase in rectal temperature may be due to release of mediators of inflammation viz, prostaglandins, bradykinins and interleukins following trauma and fracture. 


\section{Recovery}

A smooth recovery from general anaesthesia was observed after 10 to 30 minutes of turning off the isoflurane vaporizer. Raghunath et al. (2012) also maintained adequate general anaesthesia using isoflurane @ 1.0 to 2.0 MAC. In present study MAC for isoflurane ranged from 1.0 to 2.5. This could be attributed to different anaesthetic protocols used for induction of general anaesthesia.

\section{Appearance of $\beta$-tricalcium phosphate}

At day $90^{\text {th }}$, a radiograph in both the views was not able to delineate the granules from osseous tissue. The resemblance in radio-opacity of $\beta$-TCP and osseous tissue may be due to its resorption and osteoconductive properties. Jang et al. (2008) has also observed that an ideal bone graft should resorb fully and also provide three dimensional matrix to support bone ingrowth and on growth during resorption. On the same lines, Yamasaki et al. (2009) observed that the radio-opacity of the TCP decreased in a time dependent manner and was available on X-ray films at 12 weeks after implantation, but the margins of the implants were not clear indicating the resorption of $\beta$-TCP.

\section{Radiographic score}

At $90^{\text {th }}$ day, the mean radiographic score was highest $(4.50 \pm 0.22)$ for group $\mathrm{T} 3$ and it was followed by the score of $4.33 \pm 0.88$ in group T2, showing osseous callus in evolution with presence of periosteal proliferation or exuberant osseous callus in evolution. The mean radiographic score was minimum $(2.86 \pm 0.88)$ for group $\mathrm{T} 1$ at $90^{\text {th }}$ day showing organized periosteal proliferation.

The increase in mean radiographic score may be attributed to the progress in fracture healing at different intervals. In group T2, $\beta$-TCP implanted at fracture site probably acted as an osteoconductive material and leaded to increase in bone formation, hence, this bone substitute contributed to increase in radiographic score. The observation is well corroborated with the findings of Neamat et al. (2009) who stated that after resorption of Cerasorb M ( $\beta$-TCP), the bone was regenerated completely.

In group T3, the mean radiographic score was noticed highest at $90^{\text {th }}$ day expressing that fracture healing was better than rest of the two groups. This could be attributed to the role of PRP as an osteoinductive material in fracture repair as Fortier et al. (2011) has described the PRP as a milieu of growth factors, cytokines, perhaps some RBC's and all the proteins. A PRP clot serves as a fibrin matrix which acts as a scaffold for tissue repair and reservoir for retention and slow release of growth factors.
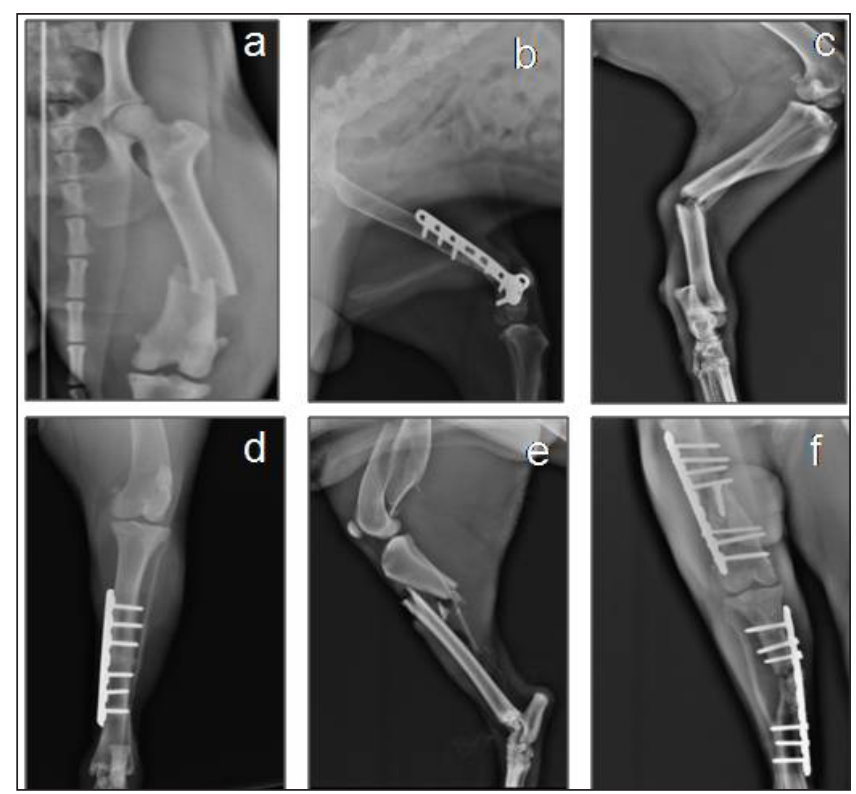

Fig. 2: Radiographic appearance of fracture (a), (c) and (e) at day 0 (b) at day 90 in group T1 (d) at day 90 in group T2 (e) at day 90 in group $\mathrm{T} 3$

Table 3: Mean radiographic score at different intervals in three groups of animals

\begin{tabular}{lll}
\hline Groups & Days & Mean radiographic score \\
\hline $\mathrm{T} 1$ & 0 & $0.00 \pm 0.00^{\mathrm{c}}$ \\
& 30 & $1.14 \pm 0.26^{\mathrm{bc}}$ \\
& 60 & $1.86 \pm 0.59^{\mathrm{ab}}$ \\
& 90 & $2.86 \pm 0.88^{\mathrm{a}}$ \\
$\mathrm{T} 2$ & 0 & $0.00 \pm 0.00^{\mathrm{c}}$ \\
& 30 & $1.83 \pm 0.31^{\mathrm{b}}$ \\
& 60 & $2.83 \pm 0.60^{\mathrm{a}}$ \\
$\mathrm{T} 3$ & 90 & $4.33 \pm 0.88^{\mathrm{a}}$ \\
& 0 & $0.00 \pm 0.00^{\mathrm{c}}$ \\
& 30 & $1.50 \pm 0.22^{\mathrm{b}}$ \\
& 60 & $3.17 \pm 0.17^{\mathrm{a}}$ \\
& 90 & $4.50 \pm 0.22^{\mathrm{a}}$ \\
\hline
\end{tabular}

Note: ${ }^{a b}$ values within groups with different superscripts differ significantly $(\mathrm{p}<0.05)$. 


\section{Inflammation}

The mean inflammation score at fracture site was recorded to be significantly $(p<0.05)$ higher at 0 day in all the three groups. There was a significant reduction in mean inflammation score at $7^{\text {th }}$ day in groups T2 and T3 and at $30^{\text {th }}$ day than 0 day in all the groups. This decline was indicative of decrease in inflammation at $30^{\text {th }}$ day in affected limb. Finally, at $90^{\text {th }}$ day, the mean inflammation score reduced to almost normal values, suggesting cessation of inflammatory signs. Desouza (2012) observed clinical signs of inflammation at fracture site in affected limb at time of presentation, however; no quantification of these signs was carried out and the inflammation subsided in most of the cases after $30^{\text {th }}$ day.

\section{Weight bearing score}

\section{Weight bearing score (while standing)}

The increment in this parameter was observed post operatively at 0 day itself, showing that animals were touching the toe (score 1) or touching the paw (score 2) in all the groups. The weight bearing (while standing) improved early because most of the animals started to touch the toe or paw just after some hours of the internal fixation. Similarly, Rajhans (2013) reported that weight bearing on affected limb after internal fixation using a reconstruction plate was observed at 0 day in few cases; however others did not show weight bearing on affected limb.

The mean weight bearing score (while standing) increased gradually from 0 to $30^{\text {th }}$ day indicating that all animals were touching the toe or paw of the affected limb. It was observed better in group T3 followed by group T2 and group $\mathrm{T} 1$ at $30^{\text {th }}$ day. This improvement in score may be due to the fact that most of the animals of group T3 showed early fracture healing as also supported by the radiographic scores. Kushwaha et al. (2012) reported full weight bearing at $18^{\text {th }}$ day on affected limb after internal fixation of a radius-ulna in a non-descript dog.

In group T3, the mean weight bearing score was $2.00 \pm$ 0.00 at $90^{\text {th }}$ day as all the animals were showing full weight bearing on affected limb. This improvement in weight bearing could be attributed to better fracture healing probably attributed to local application of PRP as also suggested by the inflammation scores and radiographic scores in the present study.

Table 4: Clinical parameters at different intervals in three groups of animals

\begin{tabular}{|c|c|c|c|c|c|}
\hline Groups & Days & $\begin{array}{l}\text { Mean inflammation } \\
\text { score }\end{array}$ & $\begin{array}{l}\text { Mean weight bearing } \\
\text { score (while standing) }\end{array}$ & $\begin{array}{l}\text { Mean weight bearing } \\
\text { score (while walking) }\end{array}$ & $\begin{array}{l}\text { Mean weight bearing } \\
\text { score (while running) }\end{array}$ \\
\hline \multirow[t]{6}{*}{$\mathrm{T} 1$} & 0 & $2.43 \pm 0.20^{\mathrm{a}}$ & $0.29 \pm 0.18^{b}$ & $0.57 \pm 0.20^{b}$ & $0.00 \pm 0.00^{\mathrm{d}}$ \\
\hline & 7 & $2.00 \pm 0.00^{\mathrm{a}}$ & $0.86 \pm 0.14^{\mathrm{ab}}$ & $1.00 \pm 0.22^{b}$ & $0.00 \pm 0.00^{\mathrm{d}}$ \\
\hline & 14 & $1.14 \pm 0.14^{b}$ & $0.86 \pm 0.14^{\mathrm{ab}}$ & $1.00 \pm 0.22^{b}$ & $0.29 \pm 0.18^{\mathrm{cd}}$ \\
\hline & 30 & $1.00 \pm 0.22^{b}$ & $1.14 \pm 0.26^{\mathrm{a}}$ & $1.71 \pm 0.52^{\mathrm{ab}}$ & $1.00 \pm 0.31^{b c}$ \\
\hline & 60 & $0.71 \pm 0.18^{b c}$ & $1.43 \pm 0.30^{\mathrm{a}}$ & $1.71 \pm 0.57^{\mathrm{ab}}$ & $1.43 \pm 0.43^{\mathrm{ab}}$ \\
\hline & 90 & $0.29 \pm 0.18^{\mathrm{c}}$ & $1.43 \pm 0.30^{\mathrm{a}}$ & $2.43 \pm 0.69^{\mathrm{a}}$ & $2.14 \pm 0.63^{\mathrm{a}}$ \\
\hline \multirow[t]{6}{*}{$\mathrm{T2}$} & 0 & $2.17 \pm 0.17^{\mathrm{a}}$ & $0.33 \pm 0.21^{b}$ & $0.67 \pm 0.33^{\mathrm{c}}$ & $0.00 \pm 0.00^{\mathrm{c}}$ \\
\hline & 7 & $1.33 \pm 0.21^{b}$ & $0.67 \pm 0.21^{b}$ & $0.67 \pm 0.33^{\mathrm{c}}$ & $0.00 \pm 0.00^{\mathrm{c}}$ \\
\hline & 14 & $0.83 \pm 0.31^{b c}$ & $0.67 \pm 0.21^{b}$ & $1.33 \pm 0.49^{\mathrm{bc}}$ & $0.67 \pm 0.33^{b c}$ \\
\hline & 30 & $0.67 \pm 0.33^{b c}$ & $1.50 \pm 0.22^{\mathrm{a}}$ & $1.83 \pm 0.70^{b c}$ & $1.17 \pm 0.54^{b}$ \\
\hline & 60 & $0.50 \pm 0.22^{c}$ & $1.67 \pm 0.33^{\mathrm{a}}$ & $2.67 \pm 0.61^{\mathrm{ab}}$ & $2.33 \pm 0.61^{\mathrm{a}}$ \\
\hline & 90 & $0.17 \pm 0.17^{\mathrm{c}}$ & $1.67 \pm 0.33^{\mathrm{a}}$ & $3.33 \pm 0.67^{\mathrm{a}}$ & $3.17 \pm 0.65^{\mathrm{a}}$ \\
\hline \multirow[t]{6}{*}{$\overline{T 3}$} & 0 & $2.50 \pm 0.22^{a}$ & $0.50 \pm 0.22^{b}$ & $0.83 \pm 0.17^{\mathrm{c}}$ & $0.00 \pm 0.00^{\mathrm{c}}$ \\
\hline & 7 & $1.50 \pm 0.22^{\mathrm{b}}$ & $0.83 \pm 0.17^{b}$ & $1.17 \pm 0.31^{\mathrm{c}}$ & $0.00 \pm 0.00^{\mathrm{c}}$ \\
\hline & 14 & $0.83 \pm 0.17^{\mathrm{c}}$ & $0.83 \pm 0.17^{b}$ & $1.67 \pm 0.21^{\mathrm{bc}}$ & $0.83 \pm 0.71^{b c}$ \\
\hline & 30 & $0.50 \pm 0.22^{\mathrm{cd}}$ & $1.67 \pm 0.21^{\mathrm{a}}$ & $2.67 \pm 0.42^{\mathrm{ab}}$ & $1.33 \pm 0.21^{b}$ \\
\hline & 60 & $0.17 \pm 0.17^{\mathrm{cd}}$ & $1.83 \pm 0.17^{\mathrm{a}}$ & $2.83 \pm 0.48^{\mathrm{ab}}$ & $2.67 \pm 0.42^{\mathrm{a}}$ \\
\hline & 90 & $0.00 \pm 0.00^{\mathrm{d}}$ & $2.00 \pm 0.00^{\mathrm{a}}$ & $3.33 \pm 0.42^{\mathrm{a}}$ & $3.33 \pm 0.33^{\mathrm{a}}$ \\
\hline
\end{tabular}

Note: ${ }^{a b}$ values within groups with different superscripts differ significantly $(\mathrm{p}<0.05)$. 


\section{Weight bearing score (while walking)}

The mean weight bearing score was found to be higher in groups T2 and T3 than group T1 at $14^{\text {th }}, 30^{\text {th }}, 60^{\text {th }}$ and $90^{\text {th }}$ day. The mean weight bearing score was recorded to be highest in group $\mathrm{T} 3$ at $30^{\text {th }}, 60^{\text {th }}$ and $90^{\text {th }}$ day post operatively.

A response having fear was markedly witnessed while assessing the animals for weight bearing (while walking). The improvement in this score must have been depended upon the weight bearing score (while standing) at different time intervals as the animal showing an early weight bearing (while standing) can be predicted to express an early weight bearing (while walking) at further intervals.

\section{Mean weight bearing score (while running)}

The mean weight bearing score was also higher in group $\mathrm{T} 3$ than in group $\mathrm{T} 2$ at $30^{\text {th }}, 60^{\text {th }}$ and $90^{\text {th }}$ post operative day showing that restoration of the function was better and earlier in groups T2 and T3 than in group T1. This finding is also based on the fact that animal showing an early weight bearing (while standing) will witness an early return of limb function with full range of motion. The same has been endorsed by Cruess and Dumont (1985) who stated that bone healing can be promoted by some factors like growth hormone, thyroid hormone, calcitonin, insulin, vitamin A and D, anabolic steroids, chondroitin sulphate, hyaluronidase, anticoagulants, electric currents, oxygen and physical exercise. Early weight bearing (while standing and while walking) in group T3 in comparison to remaining two groups, might have contributed in form of physical exercise to better weight bearing score (while running) from $60^{\text {th }}$ day onwards. Further, the assessment of the weight bearing (while running) was found difficult in a clinical environment.

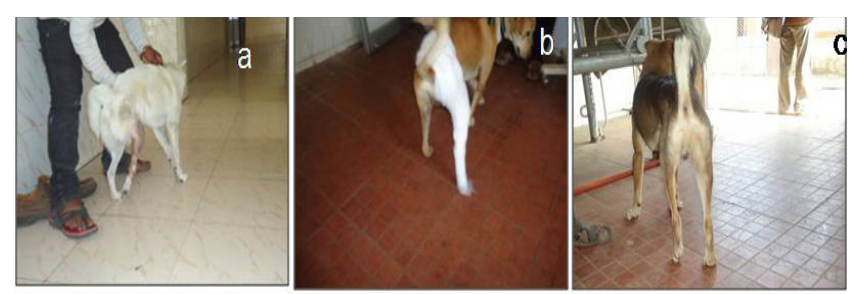

Fig. 3: Weight bearing status; (a) complete loss after fracture, (b) after $7^{\text {th }}$ day, (c) at $90^{\text {th }}$ day

\section{Complications}

The complications observed during the study were mostly related with implant failure. The failure of a locking compression plate might be due to the reason that the dog was allowed to run freely within a month. The implant failure observed in radius-ulna of a Pomeranian $(10 \mathrm{~kg})$ might be due to sub-optimal operative procedure. The high complication rate in radius-ulna fractures may be attributed to the fact that healing of radius-ulna fractures is potentially slowed by a limited blood supply, limited soft tissue around the bone (Boudrieau, 1993). Further, the bending of the plate may be attributed to the biomechanical forces applied during post operative period which vary according to temperament of animal and compliance from owner.

\section{CONCLUSION}

The composite mesh was found feasible to act as a tool for guided tissue regeneration. $\beta$-tricalcium phosphate was clinically suitable to act as osteoconductive material to improve the repair of diaphyseal fractures with bone loss. Platelet-rich plasma (PRP) was helpful as osteoinductive material to promote fracture healing with scaffolds like $\beta$-tricalcium phosphate in dogs as observed on basis of clinical and radiographic findings. Platelet-rich plasma (PRP) when used with osteoconductive material (tricalcium phosphate) was found better than osteoconductive material alone.

\section{Acknowledgements}

The authors are thankful to the Dean, College of Veterinary Science \& A.H. Jabalpur for providing required facilities for the research work.

\section{REFERENCES}

Aaboe, M., Pinholt, E.M., Hjorting-Hansen, E., Solheim, E. and Praetorius, F. 1993. Guided tissue regeneration using degradable and non-degradable membranes in rabbit tibia. Clin. Oral Impl. Res., 4: 172-176.

Balshi, T.J., Hernandez, R. E., Cutler, R.H. and Hertzog, C.F. 1991. Treatment of osseous defects using vicryl mesh (Polyglactin 910) and the branemark implant: A case report. Int. J. Oral Maxil. Impl., 6: 87-91. 
Boudrieau, R.J. 1993. Fractures of the radius and ulna. In: Slatter, D.H. (ed.). Text Book of Small Animal Surgery, 3rd Edn., Saunders, Philadelphia, pp. 1785-1798.

Cruess, R. L. and Dumont, J. 1985. Conditions influencing fracture healing. In: Newton, C.D. and Nunamaker, D.M. (ed.). Textbook of Small Animal Orthopaedics, Philadelphia: J. B. Lippincott, pp. 58-63.

Desouza, F.M. 2012. Internal fixation of distal third fractures of long bones in dogs. M.V.Sc. \& A.H. thesis (Surgery and Radiology), M.P.P.C.V.V, Jabalpur.

Fortier, L.A. 2011. Practical autologous product use - IRAP/ PRP/ Stem cells. In: Proceedings of the $50^{\text {th }}$ Brit. Equine Vet. Asso. Cong., Birmingham, 07-10, September 2011, pp. 114115.

Hayashi, A.M., Matera, J.M., Sterman F.A., Muramoto, C., Gaido, S.R. and Cortopassi, S.R.G. 2008. Evaluation of electroacupuncture in bone healing of radius-ulna fracture in dogs. Braz. J. Vet. Res. Anim. Sci., 45(5): 339-347.

Jang, B.J., Byeon, Y.E., Lim, J.H., Ryu, H.H., Kim, W.H., Koyama, Y., Kikuchi, M., Kang, K.S. and Kweon, O.K. 2008. Implantation of canine umbilical cord blood-derived mesenchymal stem cells mixed with beta-tricalcium phosphate enhances osteogenesis in bone defect model dogs. J. Vet. Sci., 9(4): 387-393.

Kasten, P., Vogel, J., Geiger, F., Niemeyer, P., Luginbuhl, R. and Szalay, K. 2008.The effect of platelet-rich plasma on healing in critical-size long-bone defects. Biomat., 29: 3983-3992.
Kushwaha, R.B., Gupta, A.K., Sharma, A. and Dwivedi, D.K. 2012. Bone plate fixation of distal radius and ulna fractures in dogs. Intas Pol., 13(2): 393-394.

Neamat, A., Gawish, A. and Gamal-Eldeen, A.M. 2009. $\beta$-Tricalcium phosphate promotes cell proliferation, osteogenesis and bone regeneration in intrabony defects in dogs. Arch. Oral Biol., 54: 1083-1090.

Pattanaik, T.K., Nath, I., Bose, V.S.C. and Kiran A.S. 2001. Bone plating of distal radioulnar fracture in a dog. Indian $J$. Vet. Surg., 22(1): 59-60.

Piermattie, D.L., Flo, G.L. and DeCamp, C.E. 2006. Hand Book of Small Animal Orthopaedics and Fracture Repair, $4^{\text {th }}$ Edn., Saunders, St. Louis, Missouri, pp. 818.

Raghunath, M., Bishnoi, A.K., Singh, S.S., Singh, M., Sharma, A. and Atri, K. 2012. Management of segmental fractures of tibia and femur by static intramedullary interlocking nailing in twelve dogs. Int. J. App. Res. Vet. Med., 10(3): 264-272.

Rajhans, M. 2013. Stabilization of splinters of long bone fracture in dog. M.V.Sc \& A.H. thesis (Surgery and Radiology), N.D.V.S.U.Jabalpur.

Yamasaki, N., Hirao, M., Nanno, K., Sugiyasu, K., Tamai, N., Hashimoto, N., Yoshikava, H. and Myoui, A. 2009. A comparative assessment of synthetic ceramic bone substitutes with different composition and microstructure in rabbit femoral condyle model. J. Biom. Mat. Res. Part B: Appl. Biomat., 91(2): 788-798. 
